\title{
Identifying the Community-Engaged Translational Research Collaboration Experience and Health Interests of Community-Based Organizations Outside of Metropolitan Atlanta
}

\section{Breanna Blaess Greteman ( $\sim$ breannalblaess@gmail.com )}

Morehouse School of Medicine

Latrice Rollins

Morehouse School of Medicine

Allisen Penn

University of Georgia

Alison Berg

University of Georgia

Eric Nehl

Emory University School of Public Health

Nicole Llewellyn

Emory University School of Medicine

Amber Weber

Emory University

Melissa George

Morehouse School of Medicine

Darrell Sabbs

Phoebe Putney Memorial Hospital

Mohamed Mubasher

Morehouse School of Medicine

Tabia Henry Akintobi

Morehouse School of Medicine

Research article

Keywords: community-engaged, rural, health, priorities, experiences, interests

Posted Date: August 28th, 2020

DOI: https://doi.org/10.21203/rs.3.rs-52357/v1 
License: (c) (i) This work is licensed under a Creative Commons Attribution 4.0 International License. Read Full License 


\section{Abstract}

Rural health research has increased over the last two decades, but there are still unknowns regarding health priorities from the perspective of rural community-based representatives. The Georgia Clinical and Translational Science Alliance (CTSA), a collaboration between four research institutions, statewide, includes a Community Engagement (CE) Program facilitating community-academic research partnerships. This study aimed to assess the health priorities, research experience, and interests from community respondents outside of Metropolitan Atlanta through the Community Engagement Facilitation Survey (CEFS). CE Program members disseminated the 11-item survey statewide at community events and professional organization meetings. Descriptive statistics were analyzed, and GIS mapping was conducted. Four-hundred six (406) surveys were analyzed, representing $83.6 \%$ of rural Georgia counties. Most frequently identified health priorities and research interests were diabetes, cancer, high blood pressure, and mental health. Results will be used to support those within rural Georgia organizations seeking to forge community-academic partnerships to address health priorities.

\section{Background}

In the scope of health services research and community engagement, it is essential to strategically engage groups or individuals that are often overlooked which includes those in rural geographies. Rural populations are defined by several parameters, including population density, U.S. Census rates, previously defined Metropolitan areas, and the area codes to which individuals commute for work (Hall, Kaufman, \& Ricketts, 2006). Research has suggested that rural communities tend to have more elderly persons, higher rates of unemployed persons, higher percentages of poor and uninsured, and higher prevalence of chronic diseases (Puma et al, 2017; Murimi \& Harpel, 2010; Buckheit et al, 2017). Studies have suggested that rural populations are more vulnerable than urban ones for these reasons as well as fewer health care providers, fragility of hospitals, and dependency on Medicare and Medicaid (Hart, Larson, \& Lishner, 2005; Murimi \& Harpel, 2010; Kilpatrick, 2009). Rural health centers have been shown to have fewer health therapy options and a lower volume capacity for patients, supporting the possibility that rural hospital patients may have different health topic priorities compared to urban populations (Ricketts, 2000; Erwin et al., 2010). Of the 159 total counties in the state of Georgia, 120 are considered rural, which is defined as having 50,000 persons or less residing in said county (State Office of Rural Health, 2020). Because of the large number of rural counties in the state, it is important to identify the priorities of rural community members from their perspective.

The engagement of community members in research often fits within the category of community-based participatory research. It empowers community members to participate in research by integrating them within the research team (Blumenthal \& DiClemente, 2013; Coughlin, Smith, \& Fernandez, 2017; Eder et al., 2018). Community members are involved in community-engaged research at various levels, from survey response to research design to sitting on community advisory boards. A goal of engaging the community in research can be to improve the physical health outcomes of participants. Studies have investigated the impact that community-based participatory research can have on community health and have identified 
various routes by which this may happen, including strengthening interventions via community insight as an added value to participation for enhancing health (Wallerstein and Duran. 2006). Using communityengaged research contributes to meeting a defined end, including increased participation and retention in future health research, reduced neonatal mortality rates, and simply to gain insight into the priorities and needs of the community (Domecq et al., 2014; Bath \& Wakerman, 2015; Etchegary et al, 2017).

Initiatives such as Rural Healthy People 2020 have formalized the process of surveying rural communities and began with Healthy People 2010, which focused on improvements specifically in rural health (Bellamy, Bolin, \& Gamm, 2011). This initiative identified chronic diseases such as diabetes, heart disease, and stroke, as well as access to quality health care services, were top priorities from respondents (Bellamy, Bolin, \& Gamm, 2011; Gamm \& Hutchison, 2003). Upon assessing the health priorities of rural community members, researchers have suggested that rural residents focus more on water pollution and sewage/water issues more than urban residents, who are more focused on built environment issues and air pollution (Wu et al., 2017; Bernhard et al, 2013). Surveys of Spanish-speaking farmworkers and rural Scottish community members have identified that chronic diseases, including diabetes and hypertension, were the two most common health topic priorities (Buckheit et al., 2017; Farmer \& Nimegeer, 2014).

For nearly 15 years, originally the National Center for Research Resources (2007-2012), and the National Center for Advancing Translational Sciences (2012-present) of the National Institutes of Health $(\mathrm{NIH})$ has supported a nationwide network of Clinical and Translational Science Awards "hubs", or funded academic health centers that serve as catalysts for clinical and translational science (Califf \& Berglund, 2010; Leshner, Terry, Schultz, \& Liverman, 2013; NCATS, 2020). Each hub, in turn, supports investigators, trainees, and their projects through an array of programs designed to turn discoveries in the laboratory, clinic, and community into medical treatments and health practice. Although hubs typically have a mission to support research within their institutions, many also collaborate across institutions, across Clinical and Translational Science Award hubs, and with colleagues across the country and world. This pooled expertise has the common goal of accelerating the translation of basic science discoveries into interventions to improve health.

The Georgia Clinical Translational Science Alliance is an alliance between Emory University, Morehouse School of Medicine, Georgia Institute of Technology, and the University of Georgia. The alliance is an inter-academic institutional magnet that concentrates basic, translational, and clinical research investigators, community clinicians, professional societies, and industry collaborators in dynamic clinical and translational research (Georgia CTSA, 2020). The Georgia CTSA was formerly the Atlanta Clinical Translational Science Institute (2007-2017) and consisted of primarily urban academic institution partners. Upon funding renewal, in 2017, the alliance now represents an expansion to include the University of Georgia, which boasts longstanding relationships with and service to rural Georgia.

Georgia CTSA CE Program aims to support community-university research partnerships, to facilitate community input into university research, and to increase health research in community settings that is both responsive and relevant to the health needs of the community. The CE Program supports 
community-university research partnerships through a required Master'-level course, community- and university-focused research capacity building workshops, pilot awards and research studio consultations that facilitate community input or co-creation of research with academic partners and increases health research in community settings (Henry Akintobi et al., 2016; Kegler et al., 2016; Rodgers et al., 2014). Together these activities are designed to enhance public trust and capacities community-engaged clinical and translational research.

The CE Program maintains a Georgia CTSA CE Steering Board as a governance structure designed to ensure that research findings and related innovations are translated to practice. Administratively support by the CE Committee, comprised of partner academic institution faculty and staff, the Steering Board strives to overcome historical trends that impede translation to the community when research, community, and agency experts do not work together as equal partners and as a single body with established rules guiding roles and functions (Henry Akintobi et al., 2011, Henry Akintobi et al., 2014). With decades of experience in community engagement research, the Steering Board maintains a community majority membership and bylaws that require that the Chair, Vice-Chair and Secretary are community representatives. The Board meets quarterly to lead CE and will also provide guidance to Georgia CTSA investigators who conduct research in the community.

To meet the goals of engaging with the community, the Georgia CTSA CE Program is involved with community-based organizations across the state of Georgia through both the Committee and the Community Steering Board. The Cooperative Extension Service at the University of Georgia provides a bridge between the academics at a university and the community at large. The Cooperative Extension Service exists throughout the United States through 112 land-grant universities to diffuse research-based information and encourage its application among citizens (Smith-Lever Act, 2008). The State Office of Rural Health has been a strategic partner of the CE Program that has been engaged in a variety of projects, including hosting two grant-writing academies for community-based organizations and health centers across the state. Other organizations represented on the Community Steering Board members include the, Georgia Department of Human Services Division of Aging Services, Navient Health, The Georgia Community Health Worker Coalition, Phoebe Putney Memorial Health System, as well as other representatives of community-based organizations and neighborhoods.

Research on rural community health priorities from the perspective of community members has not been widely conducted in the state of Georgia. Chen et al. (2020) conducted a qualitative study on the health priorities of a small sample of lymphoma survivors in rural Georgia utilizing semi-structured phone interviews. In this study, patients were frustrated by the difficulty of finding opportunities to participate in research and wanting to have more information and more reliable information on their lymphoma etiology and clinical care. Aside from this study, the data on rural community health priorities from the perspective of community members outside of Metropolitan Atlanta are sparse.

To address this lack of data and to establish a community-driven data-based approach to program implementation, the Georgia CTSA CE Program developed the CEFS. The assessment was designed to 
identify community engaged research interests, needs and experiences across the state of Georgia. The aim of this study was to detail the community-engaged processes and outcomes associated with the CEFS towards identifying the community-engaged health priorities of respondents residing outside of Metropolitan Atlanta.

\section{Methods}

All survey activities, from development to data analyses, were reviewed, monitored, and evaluated by the Georgia CTSA's CE Steering Board. The CE Program's faculty, staff, and Community Steering Board implemented a systematic approach to the development of the CEFS between February 2018 to May 2018. The CEFS was created with the goal of assessing the health topic priorities, research experience, and interests of community-based representatives and community members across the state of Georgia, and was not utilized in previous studies or published. The survey was adopted from previously administered surveys focused on assessment of community health needs towards a focus on community engaged research interests and partnership (Henry Akintobi et al., 2018). Meetings of the Community Steering Board were conducted to review survey length, and ensure culturally relevant and resonant wording, comprehension, and face validity.

The survey had a total of 11 multi-pronged, short-response, and "check all that apply" questions, and was estimated to take $\sim 5$ minutes to complete. Four questions captured respondents' occupation and/or role within their community and organizational information, including county and zip code. The remaining questions included personal and/or organizational health concerns/priorities, previous engagement in research, and interest in community-engaged research. From a list of 35 health topic areas (e.g., lung disease, obesity, rural health), respondents were asked to identify their top three health areas of concern/priority. An "other" option was provided for additional topics of interest. Respondents were then asked to identify priority population groups (e.g., babies, teens, seniors) relevant to them or their organization. Next, respondents were asked if they had previously engaged in research with a healthcare provider, a hospital partner, or a university partner. If so, respondents were prompted to provide further details. Lastly, respondents were asked to indicate their interest in working with a researcher on a community-engaged translational research project of their self-identified interests and needs.

Respondents were given the option to provide personal contact information to receive further information about potential research opportunities. Individuals were eligible to complete the survey if they identified as a community member that resides or works in the state of Georgia.

Paper surveys and electronic survey links were distributed to CE Committee and Steering Board members at bi-monthly and quarterly meetings. Members of these groups were given a stamped and addressed envelope with 25 hard-copy surveys and flyers with survey links to distribute to their community partners, along with information on the survey protocol. The instructions were to distribute the surveys and the survey link, and to send back all completed surveys using the stamped and pre-addressed envelope provided. The survey was distributed to the networks of CE Program these groups at face-to-face meeting through listserv dissemination. 
Members of the Georgia CTSA strategically disseminated the CEFS at community-based events across the state of Georgia. Specific types of events include back to school gatherings, public health conferences, faith-based meetings, and capacity building and continuing education workshops. Surveys were also collected at community events in Albany and Cordele, located in the Southwest quadrant of the state, at events that include men's health screenings and a breast cancer awareness event. Respondents could either complete a paper copy of the survey or online via a web link. Survey respondents were given incentives for completing the survey, including small items and raffle tickets to enter into a gift card drawing. All survey activities, from development to data analyses, were reviewed, monitored, and evaluated by the Georgia CTSA's CE Steering Board.

The survey was administered between June 2018 through April 2020. Data were analyzed using SPSS and Microsoft Excel software systems. All data were cleaned, and duplicates were removed utilizing SPSS's "duplicate" tool before analysis. In addition to calculating counts of each survey item, GIS maps were created for the three most frequently identified health priority topics. For this analysis, we restricted our sample to individuals living outside of the Metropolitan Atlanta counties of Fulton, DeKalb, Cobb, Gwinnett, Henry, and Clayton. Respondents identified the counties via a question in the survey that allows respondents to check which communities correspond to the ones in which they live and/or work.

\section{Results}

The Georgia CTSA CEFS database contained 691 survey responses. After cleaning the data and removing duplicate responses, 564 survey responses remained. After restricting only to surveys completed by those in non-metro counties, 406 surveys were included in our analytic sample. The most common respondent type was concerned citizens/neighborhood residents with 83 respondents $(14.1 \%)$, followed by educators with 66 respondents $(11.2 \%)$, and local/state/federal government employees with 45 respondents $(7.7 \%)$ (Table 1). There was a wide variety of respondents who did not feel that they belonged to the given categories on the survey and selected "other" for their respondent type. The most common of these "other" respondent types were students with 15 respondents, emergency medical service personnel/paramedics with seven respondents, and service workers with six respondents. 
Table 1

Organization of Respondents

\begin{tabular}{|c|c|}
\hline Respondent Type & $\mathrm{n}(\%)$ \\
\hline Concerned Citizen/Neighborhood Resident & $83(14.1)$ \\
\hline Educator & $66(11.2)$ \\
\hline Local/State/Federal Government Employee & $45(7.7)$ \\
\hline Faith Community Member & $40(6.8)$ \\
\hline Nurse & $38(6.5)$ \\
\hline Allied Health Professional & $36(6.1)$ \\
\hline Community Health Worker & $32(5.4)$ \\
\hline Business Owner & $27(4.6)$ \\
\hline Community Advocate & $27(4.6)$ \\
\hline Member of a Community-Based Organization & $26(4.4)$ \\
\hline Local/State/Federal Elected Official & $23(3.9)$ \\
\hline Hospital/Clinic Administrator & $21(3.6)$ \\
\hline Local Business Owner & $20(3.4)$ \\
\hline Pastor & $9(1.5)$ \\
\hline Physician & $6(1.0)$ \\
\hline Pharmacist & $2(0.3)$ \\
\hline \multicolumn{2}{|l|}{$87(14.8)$} \\
\hline Student $(n=15)$ & Paramedic/EMS ( $\mathrm{n}=7)$ \\
\hline Service Worker $(n=6)$ & Administration/Management $(n=5)$ \\
\hline Retired $(n=5)$ & Non-Profit $(n=3)$ \\
\hline Marketing $(n=2)$ & Respiratory Therapist $(\mathrm{n}=2)$ \\
\hline Certified Nursing Assistant $(\mathrm{n}=2)$ & Legal Professional $(n=2)$ \\
\hline Elementary School Staff $(n=1)$ & Corrections $(n=1)$ \\
\hline Accounting $(n=1)$ & RTAC Coordinator $(\mathrm{n}=1)$ \\
\hline FQHC Staff $(n=1)$ & FAC Extension Staff $(n=1)$ \\
\hline Domestic Violence Shelter Staff $(n=1)$ & Advocate for the Blind $(n=1)$ \\
\hline FNP Farmworker Program Staff $(n=1)$ & Ex-Military $(n=1)$ \\
\hline
\end{tabular}




\begin{tabular}{|ll|} 
NAACP Staff $(n=1)$ & Rabbi $(n=1)$ \\
\hline Volunteer $(n=1)$ & Nurse Practitioner $(n=1)$ \\
\hline Engineer $(n=1)$ & Did not specify $(n=23)$ \\
\hline
\end{tabular}

A total of 339 survey respondents provided either county or zip code information for areas where they live or where their organization serves. Of these, 336 also provided information on health priorities. Using these data, three maps were created in Tableau Version 19.2 depicting all counties represented by the survey sample (in gray, 128 of 153 rural Georgia counties, 83.6\%) superimposed with the counties from which at least one respondent indicated each of the top three health priorities for this sample (in color, see Fig. 1): diabetes (orange), cancer (green), \& high blood pressure (blue).

The three most frequently identified health priorities in this sample were diabetes with 129 responses (8.9\%), cancer with 128 responses (8.8\%), and high blood pressure with 108 responses (7.4\%) (Table 2). The three most frequently identified population groups served were seniors with 172 responses, children with 151 responses, and young adults with 138 responses (Table 3). 
Table 2

Health Topic Priorities of Respondents

\begin{tabular}{|llll|}
\hline Health Topic & $\mathrm{n}(\%)$ & Health Topic & $\mathrm{n}(\%)$ \\
\hline Diabetes & $129(8.9)$ & HIV/AIDS & $30(2.0)$ \\
\hline Cancer & $128(8.8)$ & Substance Abuse & $30(2.0)$ \\
\hline High Blood Pressure & $108(7.4)$ & Sexually Transmitted Infections & $28(1.9)$ \\
\hline Obesity & $83(5.7)$ & Lung Disease & $27(1.9)$ \\
\hline Women's Health & $71(4.9)$ & Domestic Violence & $26(1.8)$ \\
\hline Mental Health & $68(4.7)$ & Oral Health/Dental Problems & $23(1.6)$ \\
\hline Nutrition & $64(4.4)$ & Teen Pregnancy & $23(1.6)$ \\
\hline Heart Disease & $57(3.9)$ & Safe/Affordable Housing & $20(1.4)$ \\
\hline Access to Education & $49(3.4)$ & Violence Prevention & $19(1.3)$ \\
\hline Depression & $49(3.4)$ & Tobacco Use/Abuse & $18(1.2)$ \\
\hline Men's Health & $46(3.2)$ & Environmental Health & $15(1.0)$ \\
\hline Rural Health & $46(3.2)$ & Physical Disability & $15(1.0)$ \\
\hline Availability of Healthy Foods & $42(2.9)$ & Accidents & $13(0.9)$ \\
\hline Stroke & $42(2.9)$ & Kidney Disease & $13(0.9)$ \\
\hline Asthma & $41(2.8)$ & Infectious Disease & $12(0.8)$ \\
\hline 2nd /3rd Hand Smoke & $34(2.3)$ & Environment Free of Toxins & $11(0.7)$ \\
\hline Public Safety & $34(2.3)$ & Liver Disease & $5(0.3)$ \\
\hline Local Emergency Health Services & $31(2.1)$ & & \\
\hline
\end{tabular}


Table 3

Population Group Priorities of Respondents

\begin{tabular}{|llll|}
\hline \multicolumn{4}{|l|}{$\begin{array}{l}\text { "What population groups are a priority for you or your organization? } \\
\text { (Check all that apply)" }\end{array}$} \\
\hline Population Group & $\mathrm{n}(\%)$ & Population Group & $\mathrm{n}(\%)$ \\
\hline Seniors & $172(14.2)$ & People with Disabilities & $100(8.2)$ \\
\hline Children & $151(12.4)$ & Rural & $100(8.2)$ \\
\hline Young Adults & $138(11.4)$ & Babies & $95(7.5)$ \\
\hline Mature Adults & $118(9.7)$ & Pregnant Women & $69(5.7)$ \\
\hline Youth & $118(9.7)$ & Urban & $38(3.1)$ \\
\hline Teens & $115(9.4)$ & & \\
\hline
\end{tabular}

Out of the 406 respondents, 27 of them had previously engaged in research with a University partner (6.7\%), 33 had previously engaged in research with a Healthcare provider (8.1\%), and 23 had previously engaged in research with a Hospital partner (5.7\%) (Table 4). Of the survey respondents, $180(48.6 \%)$ were interested in working with a researcher on a community-engaged translational research project.

Table 4

Research Experience of Respondents

\begin{tabular}{|ll} 
Yes $(n=27)$ & No $(n=359)$ \\
Yes $(n=33)$ & No $(n=326)$ \\
Yes $(n=23)$ & No $(n=336)$
\end{tabular}

Of these 180 respondents, the most frequently identified research interests were on the health topics of diabetes with 72 responses $(6.9 \%)$, high blood pressure with 72 responses $(6.9 \%)$, and mental health (6.5\%) (Table 5). 
Table 5

Research Interests of Respondents

\begin{tabular}{|llll|}
\hline Yes $(\mathrm{n}=180)$ & & No $(\mathrm{n}=190)$ & $\mathrm{n}(\%)$ \\
\hline Health Topic & $\mathrm{n}(\%)$ & Health Topic & $21(2.0)$ \\
\hline Diabetes & $72(6.9)$ & Public Safety & $21(2.0)$ \\
\hline High Blood Pressure & $72(6.9)$ & Sexually Transmitted Infections & $20(1.9)$ \\
\hline Mental Health & $67(6.5)$ & Domestic Violence & $19(1.8)$ \\
\hline Obesity & $60(5.8)$ & Lung Disease & $19(1.8)$ \\
\hline Cancer & $56(5.4)$ & Tobacco Use/Abuse & $18(1.7)$ \\
\hline Nutrition & $52(5.0)$ & Teen Pregnancy & $17(1.6)$ \\
\hline Women's Health & $52(5.0)$ & Kidney Disease & $17(1.6)$ \\
\hline Heart Disease & $48(4.6)$ & Oral Health/Dental Problems & $16(1.5)$ \\
\hline Depression & $41(4.0)$ & 2nd /3rd Hand Smoke & $14(1.4)$ \\
\hline Rural Health & $41(4.0)$ & Safe/Affordable Housing & $13(1.3)$ \\
\hline Availability of Healthy Foods & $40(3.9)$ & Physical Disability & $12(1.1)$ \\
\hline Substance Abuse & $35(2.4)$ & Violence Prevention & $11(1.0)$ \\
\hline Access to Education & $34(3.3)$ & Accidents & $11(1.0)$ \\
\hline Stroke & $31(3.0)$ & Infectious Disease & $9(0.9)$ \\
\hline Men's Health & $30(2.9)$ & Environmental Health & $9(0.9)$ \\
\hline HIV/AIDS & $26(2.5)$ & Environment Free of Toxins & $5.5)$ \\
\hline Asthma & $21(2.0)$ & Liver Disease & \\
\hline
\end{tabular}

\section{Discussion}

This report aimed to identify the health priorities, research experiences and interests of respondents to the Georgia CTSA's CEFS in rural Georgia Counties. In our sample, respondents identified diabetes, cancer, and high blood pressure as their top health priorities for themselves or the organization they represent. GIS maps of these data show that respondents who identified diabetes as a priority and provided their zip code were highly prevalent in the southwest quadrant of the state, and in the counties east of Atlanta (Fig. 1). Similarly, these regions of the state contained respondents who identified cancer and blood pressure as health priorities and provided their zip code (Fig. 1).

Our findings were similar to past research identifying chronic diseases as health priorities in rural communities in other states (Buckheit, et al., 2017; Farmer \& Nimegeer, 2014; Gamm \& Hutchison, 2003). 
Not surprisingly, our results were very similar to those found in the Rural Healthy People 2020 initiative, with chronic diseases such as diabetes and high blood pressure being top priorities (Bellamy, Bolin, \& Gamm, 2011).

Our findings were similar to a recent study conducted among rural Georgia cancer patients. Findings indicated that respondents had not participated in research often, usually due to a lack of access to research opportunities (Chen et al., 2020). However, this study focused on priorities from an individual perspective where ours focused on involvement of individuals from an organization-based standpoint. Of our 406 respondents, only $27(6.7 \%)$ individuals had conducted research in the past with a University partner, 33 (8.1\%) with a healthcare partner and 23(5.7\%) with a hospital partner (Table 4). While these individuals accounted for a very small percentage of our sample, it is important to reflect that the goal of the CEFS was to garner community insights towards data-informed approaches to increase communityengaged research among individuals that may not have known of the concept beforehand. Additionally, 180 of the respondents (48.6\%) who responded to the item indicating if they were interested in conducting research in the future. This finding suggests that although respondents may not have prior community-engaged research experience, they are interested in doing so.

Our data did have some findings that differed from other reports on identifying health topic priorities of community members from the perspective of community members. While some studies had found that environmental health issues were priorities in their results (Wu et al., 2017; Bernhard et al., 2013)., we did not find this. Among the identified health priorities of respondents in this report, "environmental health" and "an environment free of toxins" ranked 29th and 34th, respectively. An explanation for this could be that the events we attended to increase survey completion were focused on chronic diseases and less on environmental health. This finding could also be due to a general lack of knowledge in the community on environmental health and more of a focus on preventing and treating highly prevalent diseases such as diabetes and high blood pressure.

A surprising finding was mental health being identified as one of the top three health topics that respondents would be interested in being paired with an academic partner to collaboratively conduct research (Table 5). The two health topics that were identified more frequently in this item were diabetes and high blood pressure, which are consistent with our health topic priorities. This finding suggests that there may be increased attentiveness to mental health in rural Georgia, especially by community members interested in engaging in research with an academic partner. It is, however, known that mental health services are limited in rural regions and could suggest that improvements may be needed.

There were several strengths of this study. First, there has not yet been a report that focuses solely on the health priorities of Georgia residents outside of Metropolitan Atlanta. Since Atlanta and its surrounding metro area have a wealth of resources for health care and research opportunities for citizens, it is important to focus on an area of the state that does not have the same resources readily available. Results can be utilized to facilitate community-academic research partnerships due to the Georgia CTSA's 
reach in both community and academic spheres. This report can also influence how other research institutions work toward expanding their research in rural communities.

Another strength of this process is that we were able to use our strong community connections-through our partner institutions and the community health workers on the team-who made it possible for us to attend and collect surveys at different events. By utilizing these existing connections, we were able to increase awareness to communities who may not know about community-engaged research. Since these communities are often left out of academic research due to geographic distance from large research institutions, many community members are not aware that they can participate in opportunities like this. This finding was evidenced by the low levels of prior research experiences but high levels of interest in engaging in research. The increase toward community-engaged research can introduce a new way of thinking to these communities, one that can be a valuable asset to the community members where they feel hopeful when it comes to having their voice heard and used to inform or co-create in research. Similar to any instance of introducing new experiences and knowledge, it assists members of these communities in creating informed thoughts on academic research and being able to reach out to someone with whom they have already been acquainted with questions or concerns.

Our study was not without limitations. A specific limitation of this study is an inability to track how many surveys were distributed versus how many were completed. A tracking system would have reduced duplicate surveys, as we often attended events with an overlap in attendees. Another limitation is that most attended events were in the Atlanta Metropolitan area and the southwest quadrant of the state, which was reflected most notably in our GIS maps. Finally, the survey was only created in English, so we are unable to get a representation of how non-English speaking backgrounds would respond. In addition, there were some representative types lacking data. For example, only nine respondents identified as pastors, six responded as physicians, and two responded as pharmacists. Individuals in each of these organizations play an essential role in their community and would be an important addition to the CEFS database. The CEFS database will allow analysis of county/zip code-specific health priorities and interests to guide local community-academic partnership development and priority setting.

This report aimed to assess the health topic priorities and research experience and interest of respondents of the Georgia CTSA's CEFS that reside outside of Metropolitan Atlanta, in Georgia's rural counties. This survey, with a counterpart for academic researchers, is utilized to facilitate communityacademic research partnerships. There are several steps that members of the Georgia CTSA can take to improve on the data. Suggested improvements mentioned above, include a unique respondent identifier system, offering the survey in other languages, and strategically increasing respondent types based on gaps in the existing data. Moving forward, program staff are utilizing these data to create an outwardlyfacing database usable by community members and academic researchers to make connections for research. This database will include a search feature for geographic and health topic areas and is expected to be available in the coming calendar year. The implications of this report and the CEFS lie in their ability to increase knowledge and facilitate communication between those interested in conducting community-engaged research. This analysis also allows the Georgia CTSA CE Program to develop data- 
informed, community responsive support and programming to those seeking community-academic research partnerships to address health priorities in communities across the state of Georgia.

The Georgia CTSA has grown, both in the geographic region it aims to reach and the perspectives on how to best serve rural Georgians, since the creation of the CEFS. Throughout the implementation of the survey, our staff have reinforced the importance of meeting these community members where they are to both assess their needs and provide them with assistance. We understand the importance of reaching out to organizations that are not typically involved in the translational research process, including emergency medical service and ambulance staff, persons in marketing, and even those who are retirees looking to be involved in their community further. The gaps in the counties represented also presents data-informed priority geographical areas for action and outreach towards increased awareness of Georgia CTSA resources. Moving forward, we recommend that that research institutions consider these strengths, limitations lessons learned and strategies in work to increase rural community engaged research and related health promotion initiatives.

\section{Abbreviations}

CE: Community Engagement

CEFS: Community Engagement Facilitation Survey

Georgia CTSA: Georgia Clinical and Translational Science Alliance

GIS: Geographic Information System

HIV/AIDS: Human Immunodeficiency Virus/Acquired Immunodeficiency Syndrome

\section{Declarations}

\section{Ethics approval and consent to participate}

Written informed consent was obtained electronically from all individual participants prior to completing the survey. This paper focuses on evaluation of processes and products as a result of programmatic support. The data collection was undertaken as an evaluation in order to assess the performance of that specific program. The evaluation was also directed and funded by the entity that conducts the programmatic activities. Due to these factors and being that the surveys were a part of the program evaluation process, the project was deemed exempt from IRB review by the IRB at Morehouse School of Medicine.

\section{Consent for publication}


No identifying information was included in the publication of this manuscript thus no additional informed consent was needed to publish this article. All data was de-identified prior to analysis.

\section{Availability of data and material}

The dataset analyzed during this study are available from the corresponding author on reasonable request.

\section{Competing interests}

The authors declare that they have no competing interests.

\section{Funding}

This grant was supported by the National Center for Advancing Translational Sciences of the National Institutes of Health under Award Number UL1TR002378. The content is solely the responsibility of the authors and does not necessarily represent the official views of the National Institutes of Health.

\section{Authors' contributions}

BG lead creation of the manuscript, including analyzing data and writing the entirety of the methods and results sections and some of the background and discussion sections. LR and THA contributed to Georgia CTSA background, in the discussion section with implications for future research, and as direct oversight on the manuscript. EN, NL, and AW analyzed the zip-code level data and created the GIS maps. $A P, A B$, and DS provided information related to the history of the Georgia CTSA. MM assisted in creation of the survey. All authors read and approved the final manuscript.

\section{Acknowledgements}

We wish to acknowledge the hard work of the staff within the Georgia CTSA who contributed toward the collection, analysis, and storage of this community survey data.

\section{References}

1. Bath, J., \& Wakerman, J. (2015). Impact of community participation in primary health care: what is the evidence?. Australian journal of primary health, 21(1), 2-8. https://doi.org/10.1071/PY12164

2. Bellamy, G. R., Bolin, J. N., \& Gamm, L. D. (2011). Rural Healthy People 2010, 2020, and beyond: the need goes on. Family \& community health, 34(2), 182-188. 
https://doi.org/10.1097/FCH.0b013e31820dea1c

3. Bernhard, M. C., Evans, M. B., Kent, S. T., Johnson, E., Threadgill, S. L., Tyson, S., Becker, S. M., \& Gohlke, J. M. (2013). Identifying environmental health priorities in underserved populations: a study of rural versus urban communities. Public health, 127(11), 994-1004. https://doi.org/10.1016/j.puhe.2013.08.005.

4. Blumenthal, D.S., \& DiClemente, R.J. (Eds.). (2013). Community-based participatory health research: Issues, methods, and translation to practice. Springer Publishing Company

5. Bolin, J. N., Bellamy, G. R., Ferdinand, A. O., Vuong, A. M., Kash, B. A., Schulze, A., \& Helduser, J. W. (2015). Rural Healthy People 2020: New Decade, Same Challenges. The Journal of rural health : official journal of the American Rural Health Association and the National Rural Health Care Association, 31(3), 326-333. https://doi.org/10.1111/jrh.12116

6. Buckheit, C., Pineros, D., Olson, A., Johnson, D., \& Genereaux, S. (2017). Improving Health Care for Spanish-Speaking Rural Dairy Farm Workers. Journal of the American Board of Family Medicine: JABFM, 30(1), 91-93. https://doi.org/10.3122/jabfm.2017.01.160174

7. Califf, R. M., \& Berglund, L. (2010). Linking scientific discovery and better health for the nation: The first three years of the NIH's Clinical and Translational Science Awards. Academic medicine: journal of the Association of American Medical Colleges, 85(3), 457.

8. Chen, L., Payne, J. B., Dance, K. V., Imbody, C. B., Ho, C. D., Ayers, A. A., \& Flowers, C. R. (2020). Priorities for Rural Lymphoma Survivors: A Qualitative Study. Clinical lymphoma, myeloma \& leukemia, 20(1), 47-52.e3. https://doi.org/10.1016/j.clml.2019.09.599

9. Coughlin, S. S., Smith, S. A., \& Fernandez, M. E. (Eds.). (2017). Handbook of community-based participatory research. Oxford University Press.

10. Domecq, J. P., Prutsky, G., Elraiyah, T., Wang, Z., Nabhan, M., Shippee, N., Brito, J. P., Boehmer, K., Hasan, R., Firwana, B., Erwin, P., Eton, D., Sloan, J., Montori, V., Asi, N., Dabrh, A. M., \& Murad, M. H. (2014). Patient engagement in research: a systematic review. BMC health services research, 14, 89. https://doi.org/10.1186/1472-6963-14-89

11. Eder, M. M., Evans, E., Funes, M., Hong, H., Reuter, K., Ahmed, S., Calhoun, K., Corbie-Smith, G., Dave, G., DeFino, M., Harwood, E., Kissack, A., Kleinman, L. C., \& Wallerstein, N. (2018). Defining and Measuring Community Engagement and Community-Engaged Research: Clinical and Translational Science Institutional Practices. Progress in community health partnerships: research, education, and action, 12(2), 145-156. https://doi.org/10.1353/cpr.2018.0034

12. Erwin, P. C., Fitzhugh, E. C., Brown, K. C., Looney, S., \& Forde, T. (2010). Health disparities in rural areas: the interaction of race, socioeconomic status, and geography. Journal of health care for the poor and underserved, 21(3), 931-945. https://doi.org/10.1353/hpu.0.0336

13. Etchegary, H., Bishop, L., Street, C., Aubrey-Bassler, K., Humphries, D., Vat, L. E., \& Barrett, B. (2017). Engaging patients in health research: identifying research priorities through community town halls. BMC health services research, 17(1), 192. https://doi.org/10.1186/s12913-017-2138-y 
14. Farmer, J., \& Nimegeer, A. (2014). Community participation to design rural primary healthcare services. BMC health services research, 14, 130. https://doi.org/10.1186/1472-6963-14-130

15. Gamm, L., \& Hutchison, L. (2003). Rural health priorities in America: where you stand depends on where you sit. The Journal of rural health : official journal of the American Rural Health Association and the National Rural Health Care Association, 19(3), 209-213. https://doi.org/10.1111/j.17480361.2003.tb00563.x

16. Georgia CTSA (CTSA). (2020). Community Engagement. Retrieved from: http://georgiactsa.org/community/CERP.html.

17. Hall, S. A., Kaufman, J. S., \& Ricketts, T. C. (2006). Defining urban and rural areas in U.S. epidemiologic studies. Journal of urban health: bulletin of the New York Academy of Medicine, 83(2), 162-175. https://doi.org/10.1007/s11524-005-9016-3

18. Hart, L. G., Larson, E. H., \& Lishner, D. M. (2005). Rural definitions for health policy and research. American journal of public health, 95(7), 1149-1155.

https://doi.org/10.2105/AJPH.2004.042432

19. Henry Akintobi, T., Dawood, N., \& Blumenthal, D (2014). An Academic-Public Health Department Partnership for Education, Research, Practice and Governance. Journal of Public Health Management \& Practice, 20(3), 310-314. PMID: 24667192

20. Henry Akintobi, T, Goodin, L., Trammel, E., Collins, D., \& Blumenthal, D. "How do you set up and maintain a community advisory board?" Section $4 \mathrm{~b}$ of "Challenges in Improving Community Engagement in Research," Chapter 5 of The Clinical and Translational Science Awards Community Engagement Key Function Committee Task Force on the Principles of Community Engagement. Principles of Community. Engagement, $2^{\text {nd }}$ Edition. Washington, DC: U.S. Department of Health and Human Services, 2011.

21. Henry Akintobi, T., Lockamy, E., Goodin, L., Hernandez, N., Slocumb, T., Blumenthal, D., Braithwaite, R., Leeks, L., Rowland, M., Cotton, T., Hoffman, L. "Processes and Outcomes of a Community-Based Participatory Research-Driven Health Needs Assessment: A Tool for Moving Health Disparity Reporting to Evidence-Based Action". (2018). Prog Community Health Partnersh. 12(1S): 139-147. doi:10.1353/cpr.2018.0029.

22. Henry Akintobi, T., Wilkerson D., Rodgers K., Escoffery C., Haardorfer R., Kegler M. "Assessment of the Building Collaborative Research Capacity Model: Bridging the community-academic researcher divide". (2016). Journal of the Georgia Public Health Association, 6(2), 123-132. https://doi.org/10.21633/jgpha.6.213

23. Kegler MC., Blumenthal DS., Akintobi TH., Rodgers K., Erwin K., Thompson W., Hopkins E. "Lessons Learned from Three Models that Use Small Grants for Building Academic-Community Partnerships for Research". (2016). J Health Care Poor Underserved, 27(2): 527-548. doi:10.1353/hpu.2016.0076.

24. Kenny, A., Farmer, J., Dickson-Swift, V., \& Hyett, N. (2015). Community participation for rural health: a review of challenges. Health expectations : an international journal of public participation in health care and health policy, 18(6), 1906-1917. https://doi.org/10.1111/hex.12314 
25. Kenny, A., Hyett, N., Sawtell, J., Dickson-Swift, V., Farmer, J., \& O'Meara, P. (2013). Community participation in rural health: a scoping review. BMC health services research, 13, 64 . https://doi.org/10.1186/1472-6963-13-64

26. Kilpatrick S. (2009). Multi-level rural community engagement in health. The Australian journal of rural health, 17(1), 39-44. https://doi.org/10.1111/j.1440-1584.2008.01035.x

27. Liverman, C. T., Schultz, A. M., Terry, S. F., \& Leshner, A. I. (Eds.). (2013). The CTSA program at NIH: Opportunities for advancing clinical and translational research. National Academies Press.

28. Murimi, M. W., \& Harpel, T. (2010). Practicing preventive health: the underlying culture among lowincome rural populations. The Journal of rural health : official journal of the American Rural Health Association and the National Rural Health Care Association, 26(3), 273-282. https://doi.org/10.1111/j.1748-0361.2010.00289.x

29. National Center for Advancing Translational Science. About the CTSA Program. National Institutes for Health. Retrieved from: https://ncats.nih.gov/ctsa/about.

30. Preston, R., Waugh, H., Larkins, S., \& Taylor, J. (2010). Community participation in rural primary health care: intervention or approach?. Australian journal of primary health, 16(1), 4-16. https://doi.org/10.1071/py09053

31. Puma, J. E., Belansky, E. S., Garcia, R., Scarbro, S., Williford, D., \& Marshall, J. A. (2017). A Community-Engaged Approach to Collecting Rural Health Surveillance Data. The Journal of rural health : official journal of the American Rural Health Association and the National Rural Health Care Association, 33(3), 257-265. https://doi.org/10.1111/jrh.12185

32. Ricketts T. C. (2000). The changing nature of rural health care. Annual review of public health, 21, 639-657. https://doi.org/10.1146/annurev.publhealth.21.1.639

33. Rodgers, KC., Akintobi, T., Thompson WW., Evans D., Escoffery C., Kegler MC. "A Model for Strengthening Collaborative Research Capacity: Illustrations from the Atlanta Clinical Translational Science Institute." (2014). Health Educ Behav, 41(3): 267-274. doi:10.1177/109198113511815.

34. Smith-Lever Act of 2008, 7 U.S.C. §§ 341-349, (2008).

35. State Office of Rural Health, Georgia Department of Community Health (2020). SORH Maps of Georgia. Retrieved from: https://dch.georgia.gov/divisionsoffices/state-office-rural-health/sorhmaps-georgia.

36. University of Georgia Extension. (2020). Districts, Facilities and Centers. Retrieved from: https://extension.uga.edu/about/districts-facilities--and-centers.html.

37. Wallerstein, N. B., \& Duran, B. (2006). Using community-based participatory research to address health disparities. Health promotion practice, 7(3), 312-323.

https://doi.org/10.1177/1524839906289376

38. Wu, C., Evans, M. B., Wolff, P. E., \& Gohlke, J. M. (2017). Environmental Health Priorities of Residents and Environmental Health Professionals: Implications for Improving Environmental Health Services in Rural Versus Urban Communities. Journal of environmental health, 80(5), 28-36. 


\section{Figures}

Diabetes

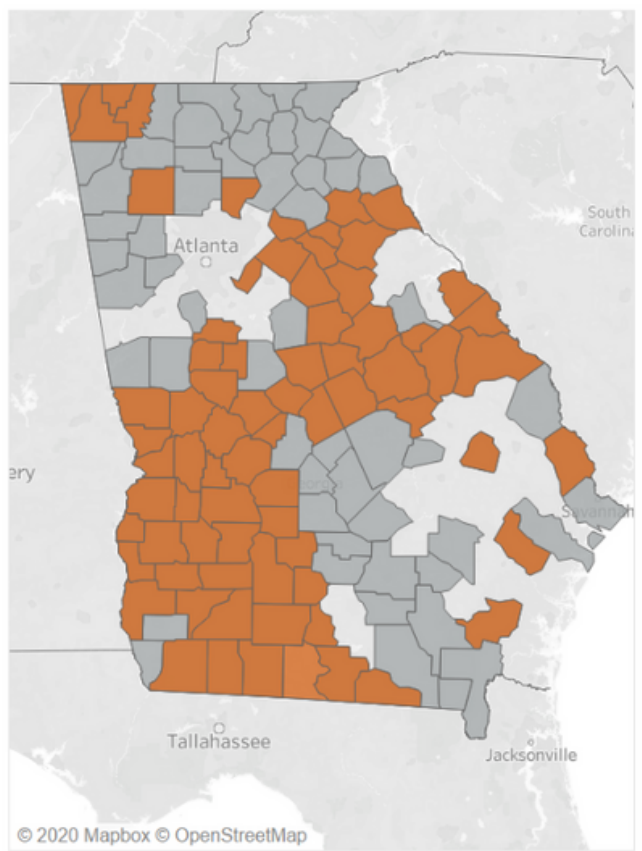

Cancer

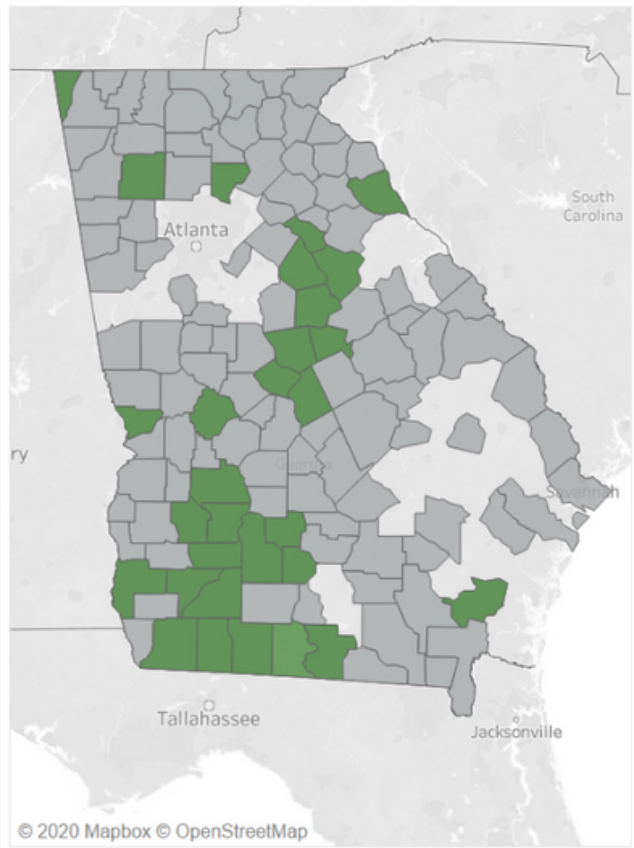

Blood Pressure

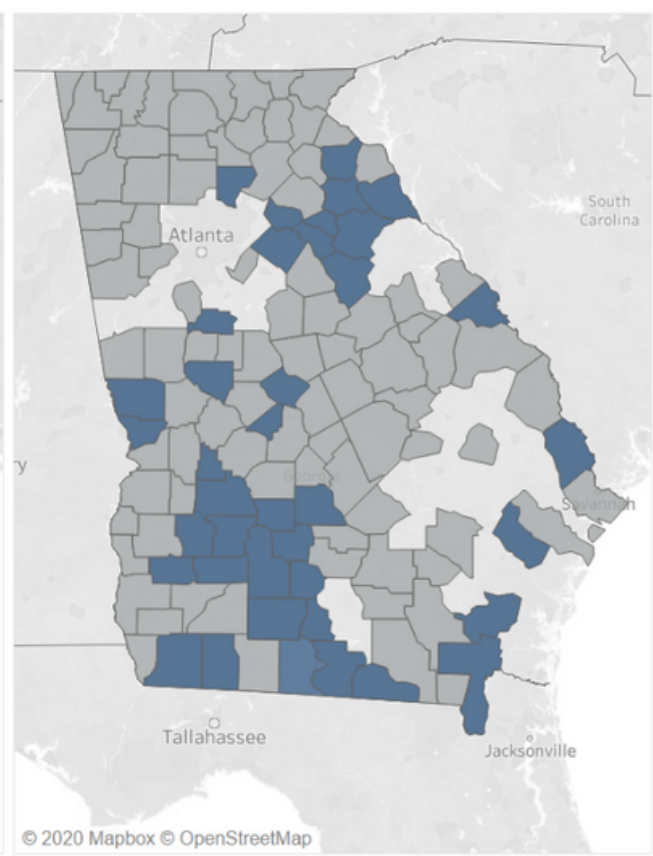

\section{Figure 1}

GIS Maps of the three Most Frequently Identified Health Topics Dark Gray indicates that there were respondents within that county. Orange coloring indicates diabetes was indicated as a priority within that county. Green coloring indicates cancer was indicated as a priority within that county. Blue coloring indicates high blood pressure was indicated as a priority within that county. 